\title{
Effect of process variables on oxidative pressurized acid leaching of copper electrorefining anode slimes
}

\author{
Sipi Seisko ${ }^{1, a}$, Jari Aromaa ${ }^{1}$, Petri Latostenmaa ${ }^{2}$, Olof Forsen ${ }^{1}$, and Mari Lundstrom ${ }^{1}$ \\ ${ }^{1}$ Aalto University, Department of Materials Science and Engineering, Vuorimiehentie 2, 02150 Espoo, Finland \\ ${ }^{2}$ Boliden Harjavalta Oy, Teollisuuskatu 1, 29200 Harjavalta, Finland
}

\begin{abstract}
Extraction of $\mathrm{Cu}, \mathrm{Ni}, \mathrm{As}$ and $\mathrm{Te}$ from copper electrorefining anode slimes was studied. Such parameters as sulfuric acid concentration, temperature and oxygen partial pressure had a positive effect on the oxidative pressurized acid leaching in the decreasing order in contrast to the solids concentration. For nickel extraction, temperature, sulfuric acid concentration, combined effect of temperature and sulfuric acid concentration as well as solids concentration and sulfuric acid concentration had a positive effect, in a decreasing order. In the case of arsenic extraction, combined effect of temperature and sulfuric acid concentration, temperature as well as sulfuric acid concentration had positive in the decreasing order. During tellurium extraction, none of the parameters investigated gave the statistically valid response. Basing on the regression analysis, appropriate models for the dissolution of copper and arsenic could be build.
\end{abstract}

\section{Introduction}

Anode slimes contain a significant amount of precious metals, therefore, their processing has a substantial economic impact on plant profitability. The first step of the anode slime treatment process is decoppering, in which copper is typically removed from slimes by oxidative pressurized acid leaching [1-3]. Additionally, a major part of nickel is extracted simultaneously [2, 3]. The aim of this research was to define the process variables having the effect on copper and other metal extraction during oxidative pressurized acid leaching.

\section{Experiments and materials}

The process variables investigated were: temperature $\left(100-160{ }^{\circ} \mathrm{C}\right)$, partial pressure of oxygen $(2-8$ bar), sulfuric acid concentration (8-16 vol.\%) and solids concentration $\left(200-400 \mathrm{~g} / \mathrm{dm}^{3}\right)$. A series of factorial test with 18 experiments, described in Table 1, was performed in a $1.1 \mathrm{dm}^{3}$ titanium (Grade 2) autoclave using sulfuric acid media with oxygen purging.

Extraction of the various elements was calculated by comparing the elemental concentration of leach residue to the initial elemental concentration in the anode slime. As the mass of slime decreases during the leaching process due to the dissolution of soluble elements, the mass of the residue can be

${ }^{a}$ Corresponding author: sipi.seisko@aalto.fi 
determined by comparing the concentration of insoluble elements left after leaching to the initial concentration of elements in the raw material. For example lead can be used as a marker element since it does not dissolve during oxidative pressurized acid leaching as it is present as insoluble $\mathrm{PbSO}_{4}$ [4]. Only traces of lead were found in the solution samples taken at the end of experiments confirming that lead remained in the residue. The initial composition of copper anode slime is presented in Table 2 .

Table 1. Performed pressurized acid leaching experiments (Exp. No. 1-18) for anode slime.

\begin{tabular}{|c|c|c|c|c|}
\hline $\begin{array}{l}\text { Exp. } \\
\text { No. }\end{array}$ & $\begin{array}{c}\text { Temperature } \\
{\left[{ }^{\circ} \mathbf{C}\right]}\end{array}$ & $\begin{array}{c}\text { Partial pressure of } \\
\mathrm{O}_{2}[\mathrm{bar}]\end{array}$ & $\begin{array}{c}\text { Solids } \\
\text { concentration }[\mathrm{g} / \mathrm{l}]\end{array}$ & $\begin{array}{c}\text { Concentration of } \\
\mathrm{H}_{2} \mathrm{SO}_{4}[\text { [vol-\%] }\end{array}$ \\
\hline 1 & 100 & 2 & 200 & 8 \\
\hline 2 & 160 & 2 & 200 & 8 \\
\hline 3 & 100 & 8 & 200 & 8 \\
\hline 4 & 160 & 8 & 200 & 8 \\
\hline 5 & 100 & 2 & 400 & 8 \\
\hline 6 & 160 & 2 & 400 & 8 \\
\hline 7 & 100 & 8 & 400 & 8 \\
\hline 8 & 160 & 8 & 400 & 8 \\
\hline 9 & 100 & 2 & 200 & 16 \\
\hline 10 & 160 & 2 & 200 & 16 \\
\hline 11 & 100 & 8 & 200 & 16 \\
\hline 12 & 160 & 8 & 200 & 16 \\
\hline 13 & 100 & 2 & 400 & 16 \\
\hline 14 & 160 & 2 & 400 & 16 \\
\hline 15 & 100 & 8 & 400 & 16 \\
\hline 16 & 160 & 8 & 400 & 16 \\
\hline 17 & 130 & 5 & 300 & 12 \\
\hline 18 & 130 & 5 & 300 & 12 \\
\hline
\end{tabular}

Table 2. The composition of copper anode slime used as raw material in the leaching experiments.

\begin{tabular}{cccccccccc}
\hline $\begin{array}{c}\mathrm{Bi} \\
{[\mathrm{mg} / \mathrm{kg}]}\end{array}$ & $\begin{array}{c}\mathrm{Se} \\
{[\mathrm{mg} / \mathrm{kg}]}\end{array}$ & $\begin{array}{c}\mathrm{Te} \\
{[\mathrm{mg} / \mathrm{kg}]}\end{array}$ & $\begin{array}{c}\mathrm{Ag} \\
{[\mathrm{mg} / \mathrm{kg}]}\end{array}$ & $\begin{array}{c}\mathrm{As} \\
{[\mathrm{mg} / \mathrm{kg}]}\end{array}$ & $\begin{array}{c}\mathrm{Ba} \\
{[\mathrm{mg} / \mathrm{kg}]}\end{array}$ & $\begin{array}{c}\mathrm{Cu} \\
{[\mathrm{mg} / \mathrm{kg}]}\end{array}$ & $\begin{array}{c}\mathrm{Ni} \\
{[\mathrm{mg} / \mathrm{kg}]}\end{array}$ & $\begin{array}{c}\mathrm{Pb} \\
{[\mathrm{mg} / \mathrm{kg}]}\end{array}$ & $\begin{array}{c}\mathrm{Sb} \\
{[\mathrm{mg} / \mathrm{kg}]}\end{array}$ \\
\hline 36000 & 73000 & 26200 & 159000 & 62800 & 26200 & 188000 & 15400 & 106000 & 21500 \\
\hline
\end{tabular}

\section{Results and discussion}

Leaching tests showed that certain elements were partially dissolved during autoclave leaching: $\mathrm{Cu}$ (67-91\%), Ni (5-100\%), As (67-89\%) and Te (19-65\%). The extraction recoveries of $\mathrm{Cu}, \mathrm{Ni}, \mathrm{As}$ and Te are presented in Table 3. The best extractions were achieved in experiment number 12 (i.e. $\mathrm{T}=160$ ${ }^{\circ} \mathrm{C}, p\left(\mathrm{O}_{2}\right)=8$ bar, [solids] $=200 \mathrm{~g} / 1$ and $\left[\mathrm{H}_{2} \mathrm{SO}_{4}\right]=16$ vol.\%, in which the highest temperature, acid concentration and oxygen partial pressure combined with the lowest amount of solids were investigated.

Figure 1a shows the anode slime SEM image prior to leaching. Three main phases of anode slime were $\mathrm{Cu}-\mathrm{As}-\mathrm{Pb}$ oxide phase (spectra 1-3), $\mathrm{Cu}-\mathrm{As}-\mathrm{Pb}-\mathrm{Se}-\mathrm{Te}-\mathrm{Sb}-\mathrm{Ag}-\mathrm{S}$ oxide phase (spectra 4-9) as well 
as $\mathrm{Ag}-\mathrm{Cu}-\mathrm{Se}-\mathrm{Te}$ oxide phase (spectra 10-12). Larger $\mathrm{Cu}-\mathrm{As}-\mathrm{Pb}-\mathrm{Se}-\mathrm{Te}-\mathrm{Sb}$-Ag-S oxide inclusions and smaller $\mathrm{Ag}-\mathrm{Cu}-\mathrm{Se}-\mathrm{Te}$ inclusions were surrounded by $\mathrm{Cu}-\mathrm{As}-\mathrm{Pb}$ oxide phase, which included traces of $\mathrm{Ag}, \mathrm{Sb}, \mathrm{Te}, \mathrm{S}$ and $\mathrm{Si}$. Additionally, the raw slime contained $\mathrm{Cu}-\mathrm{As}-\mathrm{Bi}-\mathrm{Se}-\mathrm{Te}-\mathrm{Sb}-\mathrm{Ag}-\mathrm{S}$ oxide phase, silver-rich $\mathrm{Cu}-\mathrm{Se}-\mathrm{Te}-\mathrm{Ag}$ phase, $\mathrm{Cu}-\mathrm{As}-\mathrm{Se}-\mathrm{Te}-\mathrm{Sb}-\mathrm{Ag}$ oxide phase and $\mathrm{PbSO}_{4}$ compounds.

Table 3. Extractions of $\mathrm{Cu}, \mathrm{Ni}, \mathrm{As}$ and Te after oxidative pressurized acid leaching experiments (Exp. No. 1-18).

\begin{tabular}{ccccc}
\hline Exp. No. & $\mathrm{Cu}[\%]$ & Ni [\%] & As [\%] & Te [\%] \\
\hline 1 & 69 & n.a. & 73 & 61 \\
2 & 72 & 77 & 72 & 22 \\
3 & 75 & 7 & 74 & 56 \\
4 & 86 & 67 & 71 & 62 \\
5 & 67 & n.a. & 70 & n.a. \\
6 & 74 & 13 & 71 & 19 \\
7 & 67 & n.a. & 68 & 34 \\
8 & 74 & 19 & 69 & 52 \\
9 & 78 & n.a. & 70 & 35 \\
10 & 87 & 100 & 84 & 59 \\
11 & 83 & n.a. & 70 & 49 \\
12 & 91 & 100 & 89 & 65 \\
13 & 72 & 5 & 68 & 30 \\
14 & 85 & 100 & 79 & 47 \\
15 & 78 & n.a. & 69 & 27 \\
16 & 83 & 100 & 77 & 42 \\
17 & 82 & 13 & 67 & 59 \\
18 & 80 & 16 & 68 & 28 \\
\hline
\end{tabular}

*n.a. - not available or analysis failed

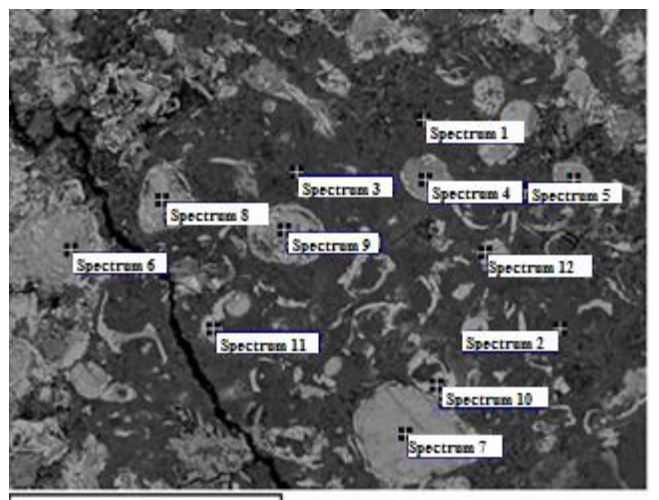

60 um

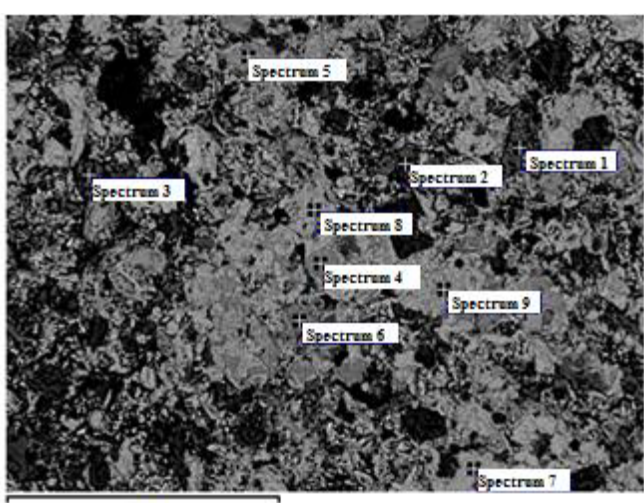

$60 \mu \mathrm{m}$

Figure 1. SEM-EDS analysis for copper anode slimes. Figure (a) on the left represents the unleached copper anode slime and (b) on the right represents leached (decopperized) anode slime (test 16).

The general morphology of the leached (decopperized) slime from test $16^{\text {th }}$ is presented in Fig. $1 \mathrm{~b}$. For the decopperized anode slime, the main phases were Te-Sb-S oxide phase (spectra 1-3), Bi-As-Se$\mathrm{Te}-\mathrm{Sb}-\mathrm{Ag}$ oxide phase with traces of $\mathrm{Cu}$ (spectra 4-6) and Se-Te-Ag phase with traces of $\mathrm{Cu}$ (spectra 7-9). Only traces of copper were shown to remain in the leached anode slime. Furthermore, $\mathrm{Cu}-\mathrm{As}-\mathrm{Bi}-$ $\mathrm{Se}-\mathrm{Te}-\mathrm{Sb}-\mathrm{Ag}$ oxide phase, Se-Te-Ag and $\mathrm{PbSO}_{4}$ phase were analyzed. Figures $1 \mathrm{a}$ and $1 \mathrm{~b}$ show that the composition of slime changed, as the base metals were extracted and the nobler elements remained in the slime. 
Several studies have investigated the effect of process variables on copper and nickel dissolution during decoppering [5-7]. In this work, the effect of process variables on extraction of $\mathrm{Cu}, \mathrm{Ni}, \mathrm{As}, \mathrm{Te}$ was investigated using the factor and regression analysis. Oxygen partial pressure was shown to have positive effect only on the copper extractions, whereas temperature and sulfuric acid concentration had more significant impact. Figure 2 illustrates the effect of process variables on dissolution of copper. Weichert et al. [6] stated that temperature was the most significant parameter in the autoclave pressure leaching of anode slimes. However, according to this study, sulfuric acid concentration was the parameter having the greatest impact. Furthermore, Weichert et al. [6] suggested that other parameters such as the sulfuric acid concentration, partial pressure of oxygen and other oxidizing agents had only a minor effect on extraction of copper. This was in contradiction with the results of this study, since oxygen partial pressure was shown to significantly affect positively on copper dissolution. Additionally, Zhang and Yan [7] reached the copper extraction near 100\% and the partial removal of tellurium and selenium as well as silver under following conditions: $T=99.85{ }^{\circ} \mathrm{C}, p\left(\mathrm{O}_{2}\right)=$ $8 \mathrm{bar}$, [solids] $=167 \mathrm{~g} / \mathrm{l}$ and $\left[\mathrm{H}_{2} \mathrm{SO}_{4}\right]=100 \mathrm{~g} / \mathrm{L}$ with the optimal leaching time of $90 \mathrm{~min}$. The suggested values of oxygen partial pressure and solids concentration were in line with the values that resulted in the best extraction of copper in this study. However, the temperature and sulfuric acid concentration were slightly lower.

\section{Scaled \& Centered Coefficients for Dissolution of copper}

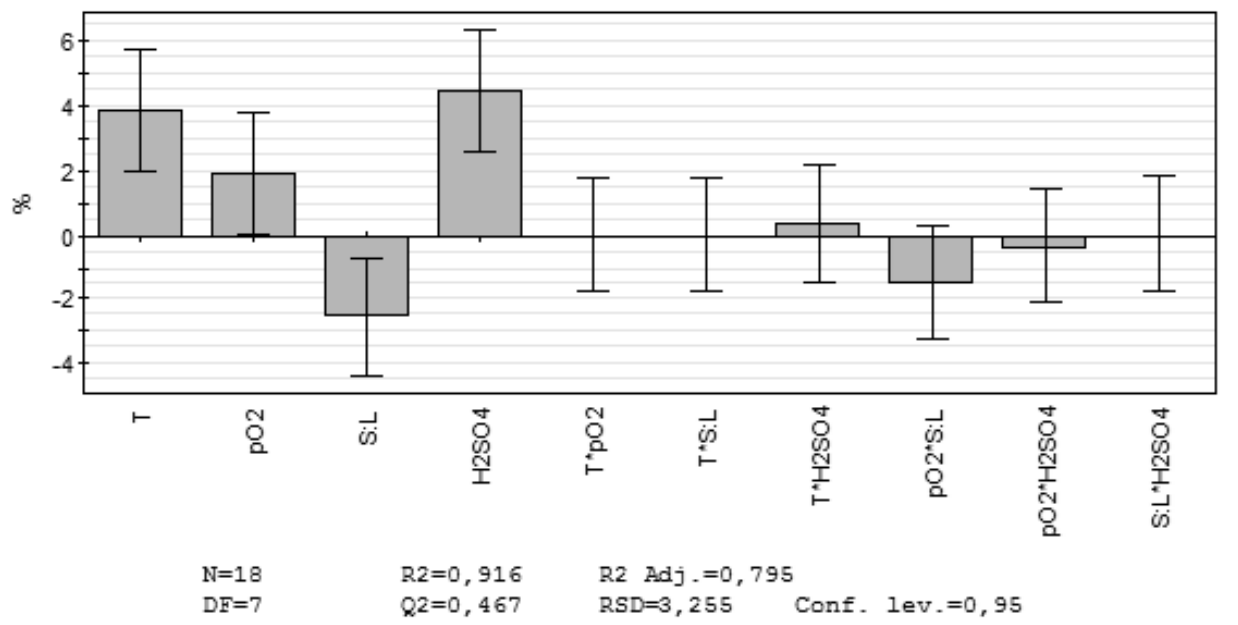

Figure 2. The effect of process variables on the dissolution of copper during oxidative pressurized acid leaching. $T$ represents temperature, $\mathrm{pO}_{2}$ the partials pressure of oxygen, $\mathrm{S}: \mathrm{L}$ solids concentration, $\mathrm{H}_{2} \mathrm{SO}_{4}$ sulfuric acid concentrations, additionally, their combined effects are presented.

The variables affecting nickel extractions were in contradiction to the literature. Sulfuric acid concentration and temperature were found to be the only affecting variables as suggested by [5]. However, Doucet and Stafiej [5] argued that sulfuric acid had a major positive effect on nickel extraction. According to the results of this study, the temperature was shown to be the dominant variable. Weichert et al. [6] suggested that sulfuric acid concentration, partial pressure of oxygen and other oxidizing agents had only a minor effect on nickel dissolution. In the current study, the combined effect of temperature and sulfuric acid concentration as well as solids concentration and sulfuric acid concentration were shown to have a positive impact on nickel extraction.

The combined effect of temperature and sulfuric acid concentration was shown to have a positive action on arsenic extraction. Furthermore, temperature and sulfuric acid concentration affected positively the process. For tellurium extraction, none of the parameters were valid, because the statistical variation exceeded the actual effect. However, despite the major statistical variation, all 
singular variables, except solids concentration, seemed to have a positive effect. Moreover, based on the regression analysis, valid models could be built only for the dissolution of copper and arsenic.

\section{Conclusions}

Extraction of $\mathrm{Cu}, \mathrm{Ni}$, As and Te from copper electrorefining anode slimes was studied by oxidative pressurized acid leaching. For copper extraction, sulfuric acid concentration, temperature and oxygen partial pressure were shown to have a positive effect in the decreasing order, whereas solids concentration had a negative effect. For nickel extraction, temperature, sulfuric acid concentration, the combined effect of temperature and sulfuric acid concentration as well as solids concentration and sulfuric acid concentration had a positive effect in the decreasing order. For arsenic extraction, the combined effect of temperature and sulfuric acid concentration, temperature as well as sulfuric acid concentration had positive action on arsenic extraction in the decreasing order. For tellurium extraction, none of the parameters investigated gave statistically valid response due to the fact that variation exceeded the actual effect. Basing on the regression analysis, valid models for the dissolution of copper and arsenic could be built.

\section{References}

1. K. Pienimäki, H. Virtanen, in Proceedings Copper (2007), p. 301

2. J. E. Hoffmann, in Proceedings EPD Congress (2000), p. 397

3. B. C. Wesstrom, in Proceedings EPD Congress (2000), p. 503

4. T. T. Chen, J. E. Dutrizac,. Can. Metall. Quart. 28(2), 127 (1989)

5. M. Doucet, J. Stafiej, in Proceedings Copper (2007), p. 173

6. K. Weichert, T. Preiss, H. Kadereit, P. Stantke, G. Leuprecht, in Proceedings Copper (2013), p. 339

7. B. Zhang, L. Yan, in Proceedings EMC (2013), 969 